\title{
Kompetensi Bidan Puskesmas dalam Meningkatkan Pelayanan Antenatal (Studi Kasus di Puskesmas Tambak Rejo, Surabaya)
}

\author{
Andy Asmara* \\ *Program Studi Pengembangan Sumber Daya Manusia \\ Sekolah Pascasarjana Universitas Airlangga Surabaya \\ Email : andy16asmara@gmail.com
}

\begin{abstract}
The daily facts indicated that an individual is the key factor to achieve organization's success. Every organization with its best performance is always related to its human resources' balanced competency. The midwife has role, function, and competencies to provide maternal services for women. The midwife's role is not only a doer, but also an organizer, an educator, and a researcher. Therefore, the midwife is expected to focus on prevention and health promotion aspect with basis of partnership, and community empowerment collaboration with other health workers in order to be readily prepare the health services for anyone who is in need.
\end{abstract}

This was qualitative research method with case study approach. The informant was the midwives of Tambakrejo Community Health Center of Surabaya. According to the data of antenatal care attendance, trained birth attendance, and perinatal care, there were 859 pregnant women, 581 persons on phase of $K 1(67.64 \%)$, and 551 persons on phase of $K 4(64.14 \%)$. The birth attendances by trained birth attendants are 513 people $(62.56 \%)$, while perinatal care recorded 570 people attending the health service (69.51\%). The data indicated the performance by the midwives of Tambakrejo Community Health Center categorized in the lowest position among 63 community health centers in
Surabaya. The result showed poor soft skill competency and poor hard skill competency on midwives. In conclusion, poor soft skill competency including personal competence and social competence should be trained and developed by obstetrics and gynecology specialist of Soewandhi Public Hospital of Surabaya. The study suggested Surabaya District Health Office needs to conduct training of technology information and computer in order to increase the service quality and to solved the problem related to hard skill competencies on technology and computer skill.

Keywords: Competencies; Midwives; Public Service

\section{PENDAHULUAN}

Berdasarkan Sustainable Development Goals (SDGs), Kementerian Kesehatan Republik Indonesia pada periode 2015-2019 menargetkan mengurangi Angka Kematian Bayi (AKB) per 1.000 kelahiran hidup dari 32 menjadi 24 AKB. Hal tersebut membutuhkan perhatian bersama dari para pengambil kebijakan.

Bidan mempunyai peran, fungsi dan kompetensi dalam memberikan asuhan kebidanan kepada wanita. Peran Bidan adalah sebagai pelaksana, pengelola, pendidik dan peneliti. Peran bidan sebagai pendidik diantaranya adalah memberikan pendidikan 
dan penyuluhan kesehatan kepada individu, keluarga, kelompok dan masyarakat tentang penanggulangan masalah kesehatan khususnya yang berhubungan dengan kesehatan ibu termasuk wanita usia subur, anak dan keluarga berencana. ${ }^{1}$

Pelayanan kebidanan adalah penerapan ilmu kebidanan melalui asuhan kebidanan kepada klien yang menjadi tanggung jawab bidan, mulai dari kehamilan, persalinan, nifas, bayi baru lahir, keluarga berencana, termasuk kesehatan reproduksi wanita dan pelayanan kesehatan masyarakat. Pelayanan Kebidanan merupakan bagian integral dari sistem pelayanan kesehatan yang diberikan oleh bidan yang telah terdaftar (teregister) yang dapat dilakukan secara mandiri, kolaborasi atau rujukan. ${ }^{2}$

Penerapan kompetensi sumber daya manusia pada organisasi sektor publik kini menjadi perhatian utama pemerintah. Setiap ibu hamil mendapatkan pelayanan antenatal sesuai standar selama kurun waktu kehamilan. Proses monitoring dan evaluasi kegiatan tersebut pada tahap awal berada di Sistem Informasi Puskesmas ${ }^{3}$. Hal ini menyiratkan komitmen kuat pemerintah dalam upaya menjamin tersedianya jaminan fasilitas kesehatan bagi masyarakat yang didukung oleh sumber daya manusia yang berkompeten pada level Puskesmas.

Fakta pada Puskesmas Tambak Rejo Surabaya menunjukkan Data Cakupan kunjungan Ibu Hamil, Persalinan ditolong tenaga kesehatan dan Pelayanan kesehatan Ibu Nifas (2017), Untuk Ibu Hamil diketahui dari 859 Ibu Hamil, Jumlah (K1) 581 orang (67.64\%) dan Jumlah (K4) 551 orang (64.14\%). Untuk Persalinan Ibu ditolong Tenaga Kesehatan 513 orang (62.56\%). Untuk Ibu mendapatkan pelayanan kesehatan Nifas 570 orang (69.51\%). Data tersebut menunjukkan posisi kinerja Bidan Puskesmas Tambak Rejo berada pada posisi terendah dari total 63 Puskesmas di Kota Surabaya. ${ }^{4}$

Kinerja tenaga kesehatan yang baik menggambarkan penguasaan terhadap kompetensi diri. Hal ini akan berdampak pada kualitas pelayanan pemeriksaan pada ibu hamil, termasuk kinerja bidan sebagai penyedia pelayanan kesehatan maternal dan neonatal. Dengan kualitas Antenatal Care (ANC) yang baik, maka ibu dan keluarga siap menjadi orang tua dan juga dapat melalui proses persalinan dengan aman. Apabila proses kehamilan, persalinan dan nifas dapat dilalui oleh seorang perempuan dengan aman, maka Angka Kematian Ibu (AKI) di Indonesia dapat ditekan. ${ }^{5}$

Bidan sebagai ujung tombak dalam upaya penurunan angka kematian dan kesakitan ibu. Untuk itu bidan harus mampu dan terampil dalam memberikan pelayanan sesuai dengan standar yang ditetapkan, karena bidan dituntut untuk memberikan pelayanan sesuai profesionalismenya. Salah satu indikator untuk menilai mutu pelayanan antenatal adalah dapat dikaji dari tingkat kualitas pelayanan antenatal dengan kepatuhan bidan dalam menerapkan standar pelayanan antenatal kehamilan yang dilakukan dalam pelayanan. ${ }^{6}$

Berdasarkan latar belakang tersebut, maka peneliti tertarik untuk melakukan penelitian dengan judul Kompetensi Bidan Puskesmas dalam meningkatkan pelayanan antenatal (Studi Kasus pada Puskesmas Tambak Rejo, Surabaya). Tujuan dari penelitian ini adalah untuk mendeskripsikan dan menganalisis Kompetensi Bidan Puskesmas dalam meningkatkan pelayanan antenatal (Studi Kasus pada Puskesmas Tambak Rejo, Surabaya).

\section{METODE PENELITIAN}

Penelitian ini menggunakan metode kualitatif pendekatan Studi Kasus. Lokasi di Puskesmas Tambak Rejo Surabaya. Didasarkan pada data Cakupan kunjungan Ibu Hamil, Persalinan ditolong tenaga kesehatan dan Pelayanan kesehatan Ibu Nifas tercatat paling rendah diantara 63 Puskesmas di Kota Surabaya.

Variabel penelitian meliputi : Sarana dan Prasarana pelayanan antenatal, Sikap dan Pandangan terhadap keragaman karakteristik pasien, Kompetensi Bidan dalam pelayanan Antenatal. Sikap dan Pandangan Bidan terhadap konsep pelayanan prima. 
Informan utama adalah Bidan sejumlah 5 orang dan Staf Seksi Kesehatan Keluarga dan Gizi Masyarakat, Dinas Kesehatan Kota Surabaya sejumlah 1 orang. Informan dipilih berdasarkan beberapa kriteria tertentu yakni pengabdian $>3$ tahun, Status Kepegawaian (PNS dan Tenaga Kontrak), Variasi usia ${ }^{7}$. Data dikumpulkan melalui wawancara mendalam dan triangulasi serta menganalisa dokumen.

\section{HASIL DAN PEMBAHASAN}

Puskesmas Tambak Rejo beralamat di Jl. Ngaglik 87 Kecamatan Simokerto, Surabaya. Kepala Puskesmas TambakRejo merupakan seorang dokter umum. Berdiri sejak tahun 1999, Puskesmas ini memberikan pelayanan Poli Umum, Poli Gigi, Poli KIA, Poli KB, Poli MTBS, Poli DDTK, Poli Konsultasi Gizi dan Kesling, Poli Psikologi, Unit Laboratorium dengan tipe puskesmas rawat jalan pagi dan sore.

Wawancara dilakukan kepada informan utama yakni bidan Puskesmas Tambakrejo menunjukkan keragaman tingkat pengalaman dalam pelayanan Antenatal.

Terkait pertanyaan sejak kapan yang bersangkutan berprofesi sebagai Bidan disampaikan pada tabel berikut:

Tabel 1. Karakteristik Informan Bidan Puskesmas Tambakrejo Surabaya

\begin{tabular}{llll}
\hline Inisial & $\begin{array}{c}\text { Usia } \\
\text { (th) }\end{array}$ & $\begin{array}{c}\text { Status } \\
\text { Kepegawaian/ } \\
\text { Pendidikan }\end{array}$ & $\begin{array}{c}\text { Lama } \\
\text { Bekerja } \\
\text { (th) }\end{array}$ \\
\hline RHP & 27 & Kontrak/D3 & 4 \\
\hline AWA & 38 & CPNS/D3 & 11 \\
\hline IST & 32 & Kontrak/D3 & 12 \\
\hline HMH & 33 & Kontrak/D3 & 12 \\
\hline EHE & 35 & Kontrak/D3 & 8 \\
\hline
\end{tabular}

Sumber : Puskesmas Tambakrejo, 2019.

Diploma 3 Kebidanan merupakan bidan pelaksana yang memiliki kompetensi untuk melaksanakan praktiknya baik diinstitusi pelayanan maupun praktik perorangan. ${ }^{8}$

Perbandingan usia diantara bidan tidak memperlihatkan perbedaan yang signifikan. Secara umum perbedaan hanya terletak pada masa kerja dan jumlah pengalaman yang didapatkan. Pada umumnya bidan mempunyai kompetensi dalam pemeriksaan ibu hamil terutama Bidan yang lebih senior dan sudah bekerja selama lebih lama. Hal ini memberikan banyak pengalaman dan pembelajaran bagi bidan. Sebagian besar diantara mereka telah memiliki keterampilan yang mahir dalam melakukan pemeriksaan fisik kepada setiap ibu hamil. ${ }^{9}$

\section{Sikap dan Pandangan terhadap Sarana dan Prasarana pelayanan Antenatal}

Pada prinsipnya fungsi sarana dan prasarana di Puskesmas Tambakrejo digunakan dalam menunjang pelaksanaan pelayanan Antenatal kepada Pasien. Namun ditemukan fakta bahwa :

"Terbatasnya ruangan pelayanan dengan jumlah pasien yang ada.”(HMH)

"Ruangan pelayanan sempit dan tempat tidur tidak sesuai dengan jumlah pasien, alat-alat medis seperti dopler dan timbangan badan sudah rusak atau tidak maksimal." (IST)

Bidan memberikan pelayanan kebidanan yang berkesinambungan dan paripurna, berfokus pada aspek pencegahan, promosi dengan berlandaskan kemitraan dan pemberdayaan masyarakat bersama-sama dengan tenaga kesehatan lainnya untuk senantiasa siap melayani siapa saja yang membutuhkannya, kapan dan dimanapun dia berada $^{8}$. Untuk menjamin kualitas tersebut diperlukan suatu standar sarana dan prasarana sebagai acuan untuk melakukan segala tindakan dan asuhan yang diberikan dalam seluruh aspek pengabdian profesinya kepada individu, keluarga dan masyarakat, baik dari aspek input, proses dan output.

Keterbatasan akan mempertegas anggapan masyarakat bahwa Pegawai pemerintahan dianggap kurang kecepatan, profesionalisme, dan efisiensi dalam pelayanan kepada publik. ${ }^{10}$

Kondisi demikian akan menjadi hambatan bidan dalam memberikan pelayanan kepada pasien. Maka sudah seharusnya bidan 
bekerjasama dengan petugas kesehatan lain untuk meningkatkan pelayanan kesehatan kepada ibu dan keluarga. ${ }^{8}$ Puskesmas Tambakrejo seharusnya berkoordinasi dengan Dinas Kesehatan Kota Surabaya agar keterbatasan tersebut dapat diatasi.

Memaksimalkan program kerja bina wilayah puskesmas sebagai wujud pelayanan di luar gedung juga dapat digunakan sebagai solusi. Membangun sinergitas antara Bidan Puskesmas dengan forum pimpinan Kelurahan, RW, RT dan para Kader Kesehatan. Untuk melakukan sweeping ibu hamil dan program penyuluhan untuk kesehatan ibu dan anak serta memberikan penyuluhan tentang bagaimana seharusnya sikap ibu hamil untuk memperhatikan kondisi fisiknya. ${ }^{11}$

\section{Sikap dan Pandangan terhadap keragaman karakteristik pasien}

Pelayanan antenatal pada prinsipnya membutuhkan pemahaman secara menyeluruh terkait kondisi sosial yang berada disekitar wilayah kerjanya. Sehingga diharapkan dengan demikian terjadi hubungan sosial yang baik antara Bidan dan Pasien.

Hal menarik ditemukan pada wawancara yang dilakukan pada tanggal 7-8 Februari 2019 adalah sebagian masyarakat masih belum memahami bahwa Puskesmas bertanggungjawab terhadap pasien yang berdomisili diwilayah kerja Puskesmas. Masih ditemukan pasien yang berdomisili wilayah lain namun kontrol ke Puskesmas Tambakrejo. Secara administrasi maka hal ini akan menghambat proses penanganan pasien.

Seperti yang dikutip pada wawancara berikut :

"Masih adanya ibu hamil yang ber_KTP tidak sesuai dengan domisilinya. Ibu Hamil ber $\mathrm{KTP} / \mathrm{KSK}$ wilayah kerja puskesmas tetapi tinggal di luar wilayah kerja Puskesmas tiba-tiba melahirkan di Rumah Sakit lalu minta rujukan ke puskesmas atau mendekati persalinan minta rujukan ke puskesmas atau tinggal di luar wilayah kerja tetapi kontrolnya masih di puskesmas. Terutama wilayah elit yang tidak tersentuh
Posyandu" (AWA)

Berdasarkan hasil wawancara tersebut menunjukkan bahwa terdapat dua hal yang menghambat pelayanan antenatal diwilayah Puskesmas Tambakrejo yakni : kawasan elit yang tidak tersentuh pelayanan posyandu, ketidaksesuaian data administrasi kependudukan pasien dengan wilayah kerja Puskesmas Tambakrejo.

Pemahaman konsep kompetensi bagi Bidan saat ini sangat luas. Ini menyiratkan konsep seperti kemampuan, perilaku, aktivitas, atau bahkan sikap kerja bidan yang ada. Komponen kompetensi kemudian harus dikombinasikan sedemikian rupa agar dapat dimanfaatkan oleh sumber daya manusia secara maksimal di dalam organisasi apapun itu. Dalam penelitian ini organisasi tersebut adalah Puskesmas Tambak Rejo Surabaya. Sebab kompetensi adalah alat kunci dalam menilai pegawai/ karyawan, perencanaan karir dan manajemen bakat sehingga dalam tahap tersebut menghasilkan kombinasi spesifik dari pengetahuan, keterampilan, dan karakteristik kepribadian lainnya yang diperlukan pegawai/ karyawan untuk pelaksanaan tugas yang efektif dalam organisasi. $^{12}$

Hambatan tersebut diatas seharusnya dapat diatasi mengingat telah menjadi bagian dari kompetensi ke 3 Keterampilan dasar point pertama yakni mengumpulkan data riwayat kesehatan dan kehamilan serta menganalisanya pada setiap kunjungan /pemeriksaan ibu hamil. ${ }^{8}$

Bidan dapat mengembangkan kluster pengaruh. Kluster Pengaruh adalah salah satu kluster yang mengindikasikan kemampuan seseorang dalam menganalisa lingkungan kerjanya. Kompetensi tersebut adalah ; kesadaran organisasional, dampak dan pengaruh, membangun hubungan (jaringan kerja $)^{13}$.

Bidan sebagai tenaga kesehatan hendaknya terus berupaya dalam meningkatkan pengetahuan, kemampuan, dan kemauannya untuk menanggulangi berbagai masalah dalam pelayanan kebidanan terutama pada pelayanan kesehatan bayi baru lahir, 
seperti memberikan pelayanan promotif dan preventif. ${ }^{14}$

Dengan penguasaan kompetensi tersebut dapat menjadi alternatif dalam membangun kerjasama yang baik antara Bidan Puskesmas, Bidan Kelurahan dan Kader Posyandu ditingkat RT dan RW.

\section{Kompetensi Bidan dalam pelayanan Antenatal.}

Keterampilan menjadi tolok ukur pasien dalam mempercayakan pelayanan Antenatal terhadap dirinya. Semakin terampil maka tercipta pelayanan yang prima. Hal tersebut diketahui pada petikan wawancara berikut :

"Penguasaan materi mengenai antenatal care maupun program yang berkaitan dengan antenatal care khususnya pasien ber-BPJS." (RHP)

Selain hal tersebut juga dibutuhkan penguasaan keterampilan penunjang seperti :

"Keterampilan berkomunikasi yang lebih baik dalam menghadapi keluhan, ketrampilan komputer dan ilmu teknologi terkini." (IST)

Kompetensi dibagi dua ; Soft Competency dan Hard Competency. Soft Competency terdiri dari 6 (enam) kelompok yakni ; Kemampuan berprestasi, Kemampuan melayani, Kemampuan memimpin, Kemampuan mengelola, Kemampuan berpikir, Kemampuan bersikap dewasa. Sedangkan Hard Competency meliputi Keterampilan (Skill), Bidang Pendidikan, dan kewenangan atau otoritas profesi dibidang tertentu. ${ }^{15}$

Kompetensi teknis menyangkut pengetahuan, ketrampilan, kemampuan dan penampilan atau kinerja pemberi layanan kesehatan. Kompetensi teknis ini berkaitan dengan cara pemberi layanan kesehatan dalam mengikuti standar pelayanan kesehatan yang telah ditentukan, yang meliputi kepatuhan, kebenaran dan konsistensi. Kompetensi teknis yang tidak dipenuhi dapat menyebabkan terjadinya penyimpangan terhadap standar pelayanan kesehatan, menurunnya mutu pelayanan kesehatan serta dapat membahayakan jiwa pasien. ${ }^{16}$
Dari hasil wawancara tersebut diatas maka dapat diketahui bahwa kompetensi bidan dalam pelayanan Antenatal dibagi menjadi dua yakni : Hard Competency yang terdiri dari Pengetahuan dan Keterampilan Antenatal care. Serta Soft Competency yang terdiri dari Sikap dan Perilaku dalam menunjang pelaksanaan pelayanan antenatal care.

Fakta dalam kehidupan sehari-hari menunjukkan bahwa manusia merupakan faktor kunci dalam mencapai keberhasilan kegiatan organisasi tidak perlu diperdebatkan lagi. Setiap organisasi yang memiliki kualitas kinerja terbaik akan selalu terhubung dengan sumber daya manusia yang memiliki keseimbangan kompetensi. Menentukan sumber daya manusia yang memiliki keseimbangan kompetensi (Soft Competency dan Hard Competency) yang mampu mewujudkan visi, misi, dan memenuhi target organisasi sangat penting bagi organisasi serta kemampuan organisasi untuk menciptakan budaya yang menjamin keberadaan sumber daya manusia yang berkompeten ini ${ }^{17}$.

Dalam pelaksanaan pelayanan dibutuhkan keseimbangan kedua kompetensi tersebut. Dari beberapa hasil wawancara ditemukan kelemahan pada Soft Competency Bidan. Soft Competency erat kaitannya dengan kecerdasan emosional. Kecerdasan emosional yang tinggi menyebabkan seseorang berhasil dalam menciptakan hubungan interpersonal yang dekat dan ramah serta memiliki penyesuaian dan pengendalian diri yang baik. Sedangkan sebaliknya, orang yang memiliki kecerdasan emosional yang rendah akan mengalami kesulitan dalam beradaptasi di lingkungan sosialnya. ${ }^{18}$ Sehingga untuk memenuhinya maka dibutuhkan pendidikan dan latihan secara berkala yang dilakukan oleh Dinas Kesehatan Kota Surabaya.

Hard Competency dan Soft Competency merupakan Kompetensi ke 1 yang harus dikuasai oleh Bidan. Bidan mempunyai persyaratan pengetahuan dan keterampilan dari ilmu sosial, kesehatan masyarakat dan etik yang membentuk dasar dari asuhan yang 
bermutu tinggi sesuai dengan budaya untuk wanita, bayi baru lahir dan keluarganya. ${ }^{8}$

\section{Sikap dan Pandangan Bidan terhadap konsep pelayanan prima.}

Pada era New Publik Service seperti saat ini maka Bidan dihadapkan pada semakin tingginya tuntutan masyarakat sebagai pasien. Maka dibutuhkan pemahaman konsep pelayanan prima dalam memberikan pelayanan Antenatal care terhadap pasien. Hal tersebut dapat diketahui pada petikan wawancara berikut :

"Petugas harus menguasai teknik pelayanan yang komprehensif khususnya tentang antenatal care serta memberikan pelayanan secara prima kepada setiap pasien." (RHP)

"Memberikan pelayanan yang terbaik, petugas lebih bersabar, selalu tersenyum dalam menghadapi keluhan pasien, selalu menggunakan kata dan nada suara yang menenangkan pasien sehingga pasien selalu merasa nyaman." (IST)

Berdasarkan wawancara tersebut, maka dapat diketahui bahwa Bidan di Puskesmas Tambakrejo dalam menerapkan konsep pelayanan prima menekankan pada penguasaan ANC disertai sikap yang ramah. Menggunakan keterampilan mendengar dan memfasilitasi. ${ }^{8}$

Keterampilan mendengar dan merasakan keluhan pasien merupakan bagian dari keterampilan interpersonal. Keterampilan interpersonal merupakan keterampilan untuk mengenali dan merespon secara layak perasaan, sikap dan perilaku, motivasi serta keinginan orang lain. ${ }^{19}$ Namun hal tersebut belum dilakukan oleh seluruh Bidan. Jika keterampilan interpersonal tersebut dapat diterapkan maka dapat memberikan kesan yang baik terhadap pasien.

\section{Sikap dan Pandangan Seksi Kesehatan Keluarga dan Gizi Masyarakat, Dinas Kesehatan Kota Surabaya terhadap Kompetensi Bidan Puskesmas Tambakrejo.}

Kompetensi menjadi syarat mutlak yang harus dipenuhi oleh seorang Bidan agar layak untuk mengamban tugas pelayanan secara langsung kepada masyarakat. Hal tersebut menjadi tugas Seksi Kesehatan Keluarga dan Gizi Masyarakat Dinas Kesehatan Kota Surabaya

Menurut NHU selaku Staf Seksi Kesehatan Keluarga dan Gizi Masyarakat, Dinas Kesehatan Kota Surabaya bahwa :

"Standart kompetensi yang harus dimiliki
Bidan ada 9 yaitu ; Bidan mempunyai
persyaratan pengetahuan dan ketrampilan
ilmu sosial. Asuhan antenatal bermutu tinggi.
Asuhan persalinan yang bersih dan aman.
Asuhan pada ibu nifas dan menyusui. Asuhan
bayi baru lahir sehat sampai dgn 1 bulan.
Asuhan bayi dan balita sehat usia 1 bulan s/d
5 tahun. Asuhan keluarga, kelompok dan
masyarakat sesuai budaya setempat. Asuhan
kebidanan pada wanita/ ibu dengan gangguan
sistem reproduksi." (NHU)

Persoalan yang terjadi di Puskesmas Tambakrejo antara lain kurangnya analisa dan pemantauan pelayanan ibu anak di wilayah kerja puskesmas serta kurangnya rasa memiliki dan tanggung jawab bersama antar staf bidan, karakteristik masyarakat yang berpindah pindah dan bermata pencaharian sebagai pedagang." (NHU)

Strategi untuk mengatasi hal tersebut :

"Untuk mengatasi maka dilakukan pembinaan oleh dr kandungan dari rs ponek yaitu RSUD dr Moh Soewandhie. Serta pelayanan di Puskesmas Tambakarejo dibuka sampai sore hari." (NHU)

Derajat kesehatan ibu dan anak di Indonesia merupakan masalah kesehatan utama. Angka Kematian Ibu di Indonesia masih tinggi dibandingkan dengan negaranegara Association of South East Asia Nations (ASEAN). Berdasarkan data Survey Demografi dan Kesehatan Indonesia (SDKI) tahun 2012, Angka Kematian Ibu (AKI) di Indonesia sebesar 395 per 100.000 kelahiran hidup. Angka Kematian Bayi di Indonesia tahun 2012 diestimasi sebesar 32 per 1.000 kelahiran hidup. ${ }^{20}$ 
Dari petikan wawancara tersebut diatas maka dapat diketahui bahwa Dinas kesehatan Kota Surabaya telah berupaya menegakkan pelaksanaan "Kode Etik Bidan Indonesia" yakni Kewajiban bidan terhadap tugasnya dan Kewajiban bidan terhadap sejawat dan tenaga kesehatan lainnya serta Kewajiban bidan terhadap profesinya. ${ }^{8}$ Upaya tersebut dilakukan secara sistematis dengan melibatkan dokter kandungan dari Rumah Sakit Soewandhie untuk memberikan pembinaan secara berkala serta membuka layanan hingga sore. Sehingga diharapkan pelayanan antenatal dapat menjamin dan menjangkau seluruh masyarakat diwilayah Tambakrejo.

\section{KESIMPULAN}

Kompetensi Bidan Puskesmas dalam meningkatkan pelayanan Antenatal (Studi Kasus pada Puskesmas Tambak Rejo, Surabaya) bertumpu pada pelayanan sesuai dengan budaya kerja puskesmas Tambakrejo yakni Profesional, Responsif, Indah, Ramah, Malu. Dengan cara meningkatkan kualitas Hard Competency berupa keterampilan pelayanan antenatal khususnya pasien berBPJS. Serta meningkatkan Soft Competency berupa keterampilan berkomunikasi yang lebih baik dalam menghadapi keluhan pasien, membudayakan sikap sabar dan ramah dalam pelayanan kepada seluruh pasien.

Saran bagi Dinas Kesehatan Kota Surabaya agar melaksanakan pelatihan teknis khususnya yang terkait dengan keterampilan berkomunikasi yang lebih baik dalam menghadapi keluhan dan keterampilan IT. Secara berkala melakukan pelatihan pelayanan Antenatal care dengan materi yang lebih update dengan situasi masyarakat terkini.

Membangun jaringan/ sistem yang memungkinkan terkoneksinya analisis data pasien yang dilakukan oleh bidan dan ibu kader ditingkat RT/ RW. Melengkapi sarana prasarana puskesmas dalam rangka menjamin pelaksanaan pelayanan antenatal yang profesional.

Sedangkan saran bagi Puskesmas Tambakrejo Surabaya agar lebih pro aktif dalam melakukan sosialisasi dan menjangkau wilayah kawasan elit atau non posyandu. Meningkatkan kesadaran akan pentingnya fungsi koordinasi antar rekan sejawat dan tenaga kesehatan lainnya dalam melaksanakan pelayanan antenatal. Memiliki rasa terbuka dan keinginan untuk terus belajar serta mengembangkan kompetensi yang ada saat ini.

\section{DAFTAR PUSTAKA}

1. Departeman Kesehatan Republik Indonesia. 2007. Standar Profesi Bidan. Pengurus Pusat Ikatan Bidan Indonesia. Jakarta.

2. Rita Yulifah, dkk. 2014. Konsep Kebidanan. Jakarta : Penerbit Salemba Medika.

3. Peraturan Menteri Kesehatan Republik Indonesia Nomor 43 Tahun 2016 tentang Standar Pelayanan Minimal Bidang Kesehatan.

4. Profil Kesehatan Kota Surabaya. 2017.

5. Sri Wahyuningsih et al. 2018. Faktor faktor yang mempengaruhi kepatuhan bidan terhadap standar pelayanan antenatal di kota palembang. JKK. April $2018 ;(5): 2$ : 96-107.

6. Manuaba, I.B.G,. 1998. Ilmu Kebidanan, Penyakit Kandungan dan KB. Jakarta : EGC.

7. Creswell, Jhon W. 2014. Penelitian Kualitatif \& Desain Riset ; Memilih diantara lima Pendekatan (Edisi ke 3 Cetakan ke II, 2018). Yogyakarta : Pustaka Pelajar.

8. Kepmenkes No. 369/Menkes SK/III/2007 tentang Standar Profesi Bidan.

9. Khairan Nisa, dkk. 2019. Analisis Faktor yang Berhubungan dengan Kinerja Bidan dalam Memberikan Pelayanan Antenatal Berkualitas Diwilayah Kerja Puskesmas Kota Bukittinggi Tahun 2018. Jurnal Ilmiah Universitas Batanghari Jambi. Volume 19, Nomor 1, Februari 2019, (Halaman 53-60)

10. Martínez, Pedro Á. L. Analysis of professional competencies in the Spanish public administration management. Journal of Work and Organizational Psychology 30 (2014) 61-66. 
11. Ridwan Lalonda, dkk. 2017. Analisis Implementasi Standar Pelayanan Minimal (SPM) Dilihat Dari Pelayanan Kesehatan Dasar di PUSKESMAS Tuminting Kota Manado. Jurnal IKMAS. 2017 : Vol 2, No 7

12. Kubeš, M. - Spillerová, D. - Kurnický, R. (2004). Manažerské kompetence : zpĤsobilosti výjimepných manažerĤ. 1. vyd. Praha: Grada Publishing.

13. Spencer,Lyle, M. Jr. and Signe M. Spencer. 1993. Competency at Work : Models for Superior Performance. New York : John Wiley \& Sons, Inc.

14. Sri Lestari Ningsih, dkk. 2018. Peran Bidan Dalam Pelaksanaan Permenkes Nomor 53 Tahun 2014 Tentang Pelayanan Kesehatan Neonatal Pada Bayi Baru Lahir Di Puskesmas Kaleroang Sulawesi Tengah. SOEPRA Jurnal Hukum Kesehatan. Vol. 4 | No. $1 \mid$ Juni 2018

15. Masdar, Sjahrazad. 2009. Manajemen Sumber Daya Manusia Berbasis Kompetensi. Surabaya : Airlangga University Press.

16. Lisa Marniyati, dkk. 2016. Pelayanan Antenatal Berkualitas dalam Meningkatkan Deteksi Risiko Tinggi pada Ibu Hamil oleh Tenaga Kesehatan di Puskesmas Sako, Sosial, Sei Baung dan Sei Selincah di Kota Palembang. Jurnal Kedokteran dan Kesehatan. Volume 3, NO. 1, Januari 2016:355-362

17. Skorková, Zuzana. Competency models in public sector. Procedia - Social and Behavioral Science 230 (2016) 226-234.

18. Goleman, Daniel. 1996. Emotional Intelligence : Why It Can Matter More Than IQ. New York : Bantam Books.

19. Dennis E. Coates. 2006. The Learning Behaviour. Washington DC : The Brookings Institution.

20. Kementerian Kesehatan Republik Indonesia. 2013. Profil Kesehatan Indonesia Tahun 2013. Jakarta : Kemenkes RI 2014. 